\title{
INVESTIGATION OF DYNAMIC CABLE-DECK INTERACTION IN A PHYSICAL MODEL OF A CABLE-STAYED BRIDGE PART I: MODAL ANALYSIS
}

\author{
E. CAETANO and A. CUNHA \\ Faculty of Engineering of University of Porto, Rua dos Bragas, 4099 Porto Codex, Portugal \\ C. A. TAYLOR \\ Earthquake Engineering Research Centre, University of Bristol \\ Queen's Building, University Walk, Bristol BS8 1TR, U.K.
}

\begin{abstract}
SUMMARY
A description of an experimental investigation involving the study of the dynamic interaction between the cables and the deck/towers system in cable-stayed bridges is presented. The work was carried out on a physical model of a cable-stayed bridge (the Jindo Bridge, in South Korea), whose characteristics of stiffness and mass have been conveniently scaled. Standard modal analysis tests were performed using both an electrodynamic shaker and a shaking table, leading to the creation of a high quality data base, characterizing the dynamic behaviour of the bridge. The study shows the existence of a clear dynamic interaction between the cables and the deck/towers system, associated with the appearance of several groups of mode shapes, at closely spaced frequencies, involving different cable movements, but similar configurations of the girder and towers.
\end{abstract}

KEY WORDS: Cable-stayed bridges; physical models; modal analysis; shaking table; cable dynamics.

\section{INTRODUCTION}

The peculiarity of the structural behaviour of cable-stayed bridges, in particular under dynamic excitations (wind, earthquakes and traffic loads), naturally requires the adoption of sophisticated 
dynamic analysis procedures. Although there has been recently a significant effort to improve numerical formulations for the modelling of the structural behaviour, it is of great interest to perform experimental tests, both on prototypes and on physical models, to improve and validate the mathematical models, and to study some peculiar forms of behaviour not yet completely understood.

Some physical models have been tested in the past ${ }^{1-3}$. However, not all of them were replicas of specific prototypes. Only in a few cases were some correlations achieved between the analytical response of the prototype and the measured response of the model to some dynamic excitation. Full-scale vibration tests on cable-stayed bridges have also been reported in the literature, as it is the case of Annacis ${ }^{4}$, Tjörn 5 or Tampico 6 bridges.

From these tests and from visual observation of other cable structures, some particular aspects associated with the dynamics of cable-stayed bridges have been identified, such as the occurrence of important stay cable oscillations, sometimes conjugated with simultaneous vibration of the deck. This phenomenon has been clearly evidenced by long-term monitoring of some modern bridges, namely Faroe ${ }^{5}$, Helgeland 7 , Ben-Ahin and Wandre ${ }^{8}$ bridges. Although there is not yet a complete knowledge of the mechanism behind these cable oscillations, several possible causes have been considered ${ }^{9}$, namely (i) excitation caused by vortex shedding from behind the pylons, the girder or the cables ${ }^{10}$, (ii) direct excitation from the wind due to turbulent flow, (iii) excitation due to oscillation of the cable supports (parametric excitation) ${ }^{11}$ and (iv) rain-induced vibration ${ }^{12}$. Each of these aspects has been the subject of recent investigations, in many cases accompanied by the development of laboratory tests on individual cables ${ }^{13}$. Considering these aspects in the study of the global behaviour of a cable-stayed bridge, some authors $5,14,15$ have stressed the significance of modelling the distributed inertia of the cables in the numerical model of the bridge, so as to include the corresponding vibration modes in the dynamic analysis of the whole structure. However, to the authors' knowledge, the degree of importance of cable vibration in terms of the dynamic response of cable-stayed bridges has not yet been fully evaluated.

Using a numerical approach, Abdel-Ghaffar and Khalifa ${ }^{15}$ emphasized the importance of complex vibrations of stay cables, which seem to be strongly coupled with the bridge deck and 
tower motions, although they are usually overlooked or treated independently in most studies of cable-stayed bridges. According to Abdel-Ghaffar and Khalifa, by discretizing each cable into small finite elements, there results new and numerous complex pure cable vibration modes, whose analytical prediction would be impossible using the linearized natural frequency expressions for the individual inclined cables. Furthermore, this model also provides coupled deck-cable motions involving bending and torsional motions of the deck, as well as vertical and swinging cable motions. These cannot be predicted using traditional finite element models, and may have a significant effect on the participation factors used in the earthquake response calculation.

The present paper describes some results of an investigation conducted at the Earthquake Engineering Research Centre of the University of Bristol (U.K.), in collaboration with the University of Porto (Portugal), with the aim of experimentally confirming the existence and importance of the interaction between the stay cables and the deck-towers system in a cablestayed bridge. This study has been performed on the physical model of a cable-stayed bridge (the Jindo Bridge, in South Korea), whose characteristics of stiffness and mass have been conveniently scaled. Standard experimental modal analysis techniques have been employed in order to identify the main dynamic parameters of the bridge, using both an electrodynamic shaker and a shaking table. Various series of mode shapes were identified at very close frequencies, involving similar configurations of the girder and towers, but different cable movements. A comparison between experimental and numerical results was made.

In order to evaluate the importance of the dynamic cable-deck interaction in terms of the response to seismic excitations, several shaking table tests were also performed, considering different types of artificial accelerograms. Results of these tests, as well as of numerical simulations, are presented in a companion paper ${ }^{16}$.

\section{THE JINDO BRIDGE PROTOTYPE}

The Jindo Bridge, designed by Rendel Palmer \& Tritton and built in South Korea ${ }^{17}$, is a three span steel cable-stayed bridge with a continuous stiffening girder, having a total length of 484 
$\mathrm{m}$. The main span is $344 \mathrm{~m}$ and the side spans are $70 \mathrm{~m}$, according to the scheme of Figure 1 . The boundary conditions of the main girder are achieved by two rocker supports at the ends, one pinned support at one of the towers and a roller at the other tower. The stays are arranged in a form of a fan converging at the top of each A-frame tower. Each tower carries 24 stays. The cables are locked coil ropes.

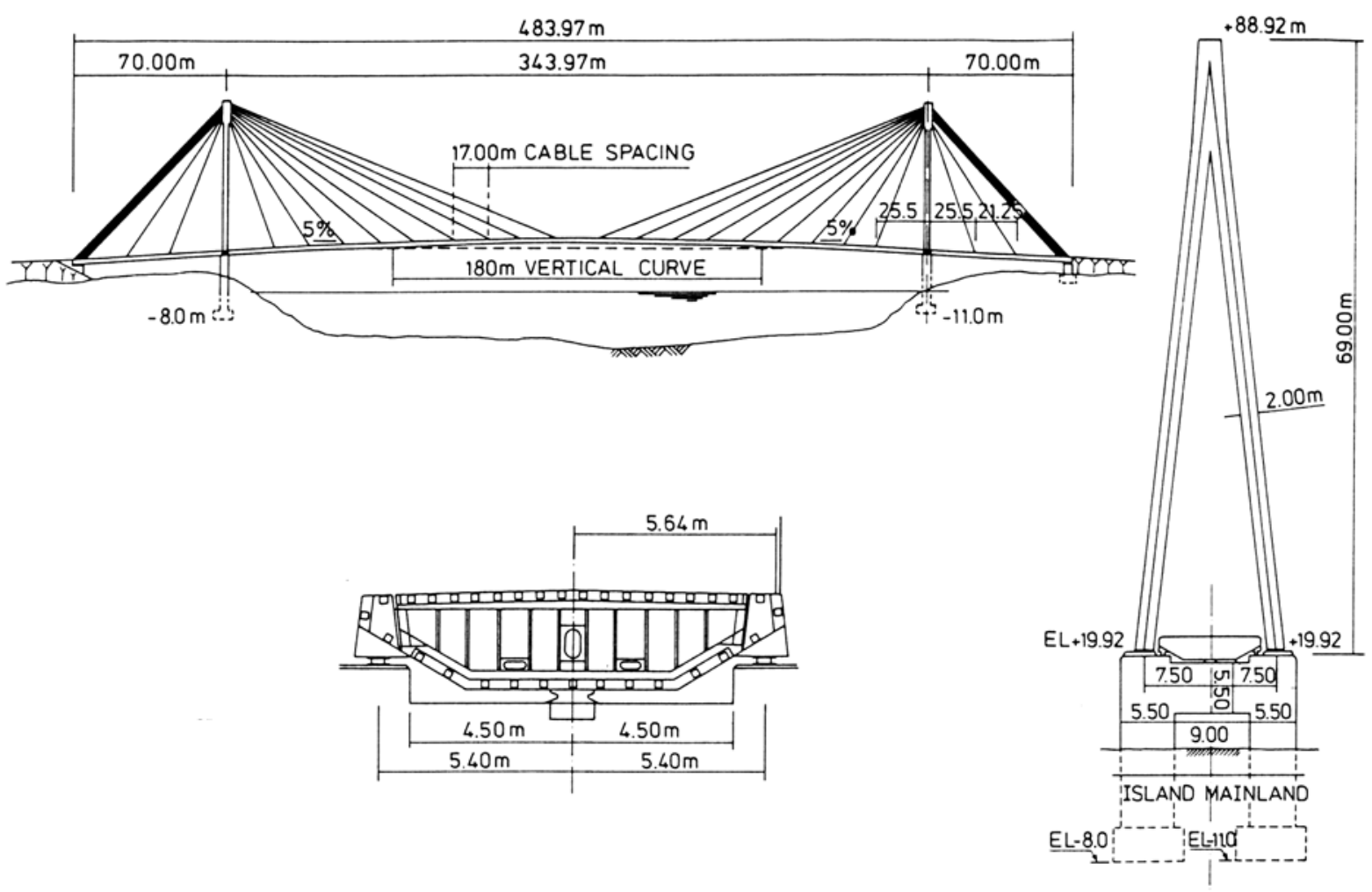

Figure 1. General characteristics of Jindo Bridge

\section{THE PHYSICAL MODEL OF JINDO BRIDGE}

The physical model of Jindo Bridge, built at the Earthquake Engineering Research Centre of the University of Bristol, can be described as a distorted small scale model with artificial mass simulation. This model was designed by Garevski ${ }^{3}$, who performed damping and seismic response measurement tests, and was slightly modified by the authors 18 , in order to study appropriately the problem of coupled cable-deck motions.

The model satisfied similarity for the bending stiffness of the girder and towers and for the axial stiffness of the cable stays. The design of new additional masses for the cables attempted to simulate correctly their continuous mass distribution while using an efficient form 
of fixation. A complete description of this design process, based on the similarity theory, was previously reported by the authors in Ref. 18 .

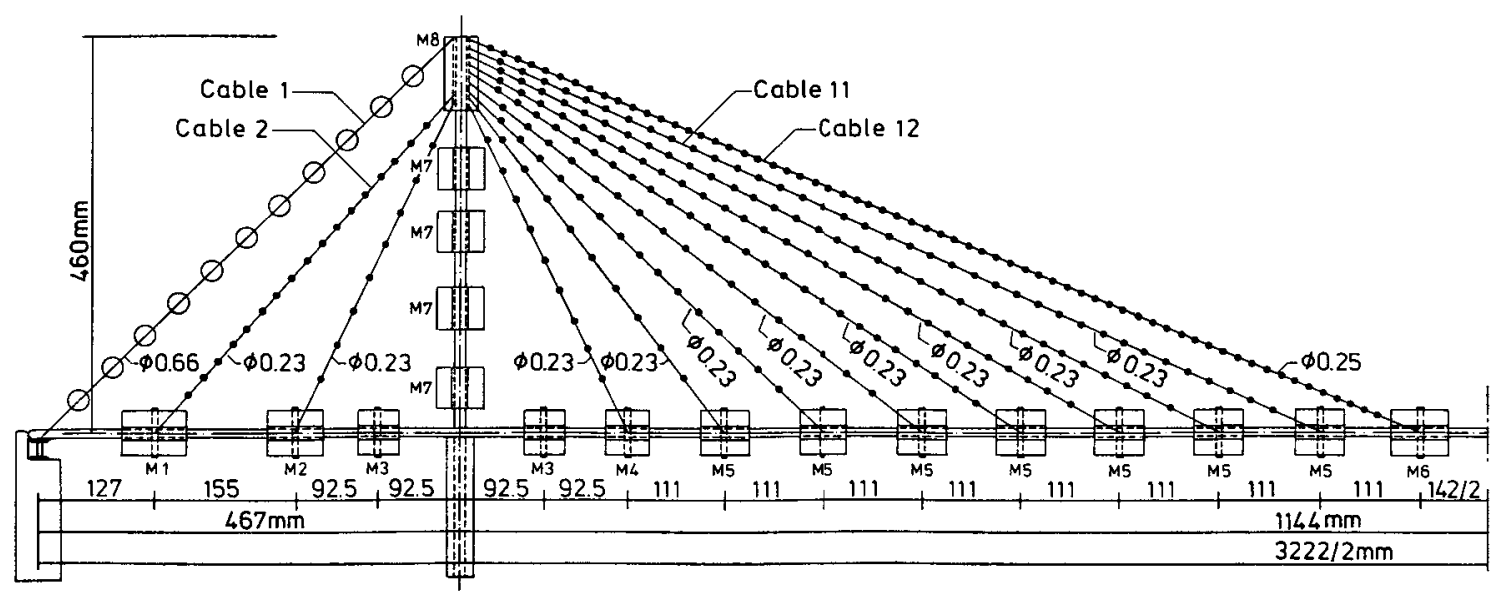

Figure 2. Overall characteristics and dimensions of the Jindo Bridge physical model

The total length of the bridge model was $3.222 \mathrm{~m}$, according to the linear scale factor $S_{L}=150$. The choice of such a small scale was conditioned by the dimensions of the shaking table, and prevented the correct scaling of all aspects of the prototype. The box cross-sections of the girder and tower legs were substituted by solid rectangular cross-sections with correctly scaled bending stiffness (but not axial stiffness), maintaining the A-shape of the towers. These components, constructed in an aluminium alloy (Young's modulus $E_{b}=72 \mathrm{GPa}$ ), had the following dimensions: girder, $25.4 \times 7.92 \mathrm{~mm}$, tower legs, $9.2 \times 8.4 \mathrm{~mm}$. The stay cables were simulated with piano wires (Young's modulus $E c=210 G P a$ ). Their axial stiffness was correctly scaled and the only difference to the prototype was on the back stays, that were made of 6 cables in the real structure, and were constituted by one piano wire with equivalent scaled area in the model. To compensate for the dead weight of such a light model, additional masses were added. Small steel plates were attached to the towers and girders by two bolts, without any further contact to minimise any stiffening effects. Small lead spheres were glued along the cables that simulated the back stays. For the other cables, smaller masses made of a zinc alloy usually used as angling weights were attached to the cables simply by pressure. A general description of the overall bridge model can be found in Figure 2, while a more detailed characterization of the model is presented in Ref. 3. Table I summarizes the values of the scale factors used. Table II shows the characteristics of the added masses. 
Table I. Scale factors of Jindo Bridge model

\begin{tabular}{lc}
\hline \multicolumn{1}{c}{ Designation } & Scale factor \\
\hline Length & $S_{L}=150$ \\
Young's modulus (deck and towers) & $S_{E}^{b}=3.07$ \\
Young's modulus (cables) & $S_{E}^{c}=0.748$ \\
Mass (deck and towers) & $S_{M}^{b}=3.07 \cdot(150)^{2}$ \\
Mass (cables) & $S_{M}^{c}=3.07 \cdot(150)^{2}$ \\
Area (deck and towers) & $S_{A}^{b}=150^{2}$ \\
Area (cables) & $S_{A}^{c}=(3.07 / 0.748) \cdot(150)^{2}$ \\
Inertia & $S_{I}^{b}=150^{4}$ \\
Force (deck, towers and cables) & $S_{F}^{b, c}=3.07 \cdot(150)^{2}$ \\
Time & $S_{t}=\sqrt{150}$ \\
Frequency & $S_{f}=(150)^{-1 / 2}$ \\
\hline
\end{tabular}

Table II. Characteristics of the added masses

\begin{tabular}{cccc}
\hline Location & $\begin{array}{c}\text { Type of } \\
\text { mass }\end{array}$ & $\begin{array}{c}\text { Number } \\
\text { of masses } \\
\text { / cable }\end{array}$ & $\begin{array}{c}\text { Total } \\
\text { mass }(\mathrm{kg})\end{array}$ \\
\hline Cable 1 & Lead & 11 & 0.306 \\
Cable 2 & Zinc & 17 & 0.0267 \\
Cable 3 & Zinc & 10 & 0.0157 \\
Cable 4 & Zinc & 10 & 0.0157 \\
Cable 5 & Zinc & 11 & 0.0173 \\
Cable 6 & Zinc & 18 & 0.0283 \\
Cable 7 & Zinc & 22 & 0.0348 \\
Cable 8 & Zinc & 32 & 0.0505 \\
Cable 9 & Zinc & 35 & 0.0552 \\
Cable 10 & Zinc & 40 & 0.0631 \\
Cable 11 & Zinc & 44 & 0.0694 \\
Cable 12 & Zinc & 64 & 0.1009 \\
\hline
\end{tabular}

\begin{tabular}{ccc}
\hline Location & $\begin{array}{c}\text { Type of } \\
\text { mass }\end{array}$ & $\begin{array}{c}\text { Total } \\
\text { mass }(\mathrm{kg})\end{array}$ \\
\hline Girder & Steel (M1) & 1.83 \\
Girder & Steel (M2) & 1.63 \\
Girder & Steel (M3) & 1.20 \\
Girder & Steel (M4) & 1.31 \\
Girder & Steel (M5) & 1.45 \\
Girder & Steel (M6) & 1.68 \\
Tower & Steel (M7) & $2 \times 0.4545$ \\
Tower & Steel (M8) & 1.007 \\
\hline
\end{tabular}

The set of final tensions on the cables from the bridge prototype was scaled according to the similitude theory, leading to the values of the prestress to be developed in the wires of the model, presented in Table III. This was achieved by turning bolts, around which the ends of the cables were wrapped, in the manner of tuning a violin. The tension in each cable was tuned indirectly using a magnetic sensor and a Fourier analyzer, taking into account the relation between the natural frequencies of the cables and the corresponding tensions, according to the vibrating chord theory ${ }^{19}$. 
Table III. Jindo Bridge model: natural frequencies of the stay cables

\begin{tabular}{ccccccc}
\hline $\begin{array}{c}\text { Cable } \\
\text { No. }\end{array}$ & $\begin{array}{c}\text { Length } \\
(\mathrm{mm})\end{array}$ & $\begin{array}{c}\text { Mass } \\
(\mathrm{kg} / \mathrm{m})\end{array}$ & $\begin{array}{c}\text { Tension } \\
(\mathrm{N})\end{array}$ & $\begin{array}{c}\text { 1st Freq. (Hz) } \\
\text { FEM (Irvine) }\end{array}$ & $\begin{array}{c}\text { 2nd Freq.(Hz) } \\
\text { FEM (Irvine) }\end{array}$ & $\begin{array}{c}\text { 3rd Freq. (Hz) } \\
\text { FEM (Irvine) }\end{array}$ \\
\hline 1 & 643.5 & 0.5258 & 123.1 & $11.46(11.89)$ & $22.61(23.78)$ & $33.42(35.67)$ \\
2 & 513.0 & 0.05205 & 13.1 & $14.72(15.46)$ & $29.30(30.93)$ & $43.82(46.39)$ \\
3 & 424.3 & 0.03724 & 9.6 & $17.90(18.92)$ & $35.46(37.84)$ & $52.35(56.76)$ \\
4 & 424.4 & 0.03723 & 8.4 & $16.94(17.70)$ & $33.57(35.39)$ & $49.56(53.09)$ \\
5 & 486.4 & 0.03577 & 8.0 & $14.64(15.37)$ & $29.06(30.74)$ & $43.00(46.12)$ \\
6 & 558.7 & 0.05076 & 10.9 & $12.89(13.11)$ & $25.39(26.23)$ & $37.92(39.34)$ \\
7 & 646.5 & 0.05375 & 12.0 & $11.22(11.56)$ & $22.40(23.11)$ & $33.53(34.67)$ \\
8 & 740.7 & 0.06816 & 13.2 & $9.14(9.39)$ & $18.26(18.79)$ & $27.39(28.18)$ \\
9 & 839.1 & 0.06581 & 14.8 & $8.95(8.94)$ & $17.44(17.87)$ & $26.15(26.81)$ \\
10 & 940.3 & 0.06711 & 16.3 & $8.20(8.29)$ & $15.90(16.57)$ & $23.84(24.86)$ \\
11 & 1043.6 & 0.06652 & 17.4 & $7.90(7.75)$ & $15.37(15.50)$ & $23.04(23.25)$ \\
12 & 1148.4 & 0.08788 & 21.5 & $5.87(6.81)$ & $7.94(13.62)$ & $10.90(20.43)$ \\
\hline
\end{tabular}

Table III summarizes the frequencies of the first three harmonics of the stay cables evaluated both on the basis of the Irvine theory ${ }^{19}$, assuming a continuous idealization of the cables, and from a finite element formulation, dividing each cable into several truss elements with lumped masses at the nodes.

\section{NUMERICAL EVALUATION OF MODAL PARAMETERS OF THE MODEL}

Although it is recognized that the behaviour of cable-stayed bridges is clearly three-dimensional and so a valid numerical analysis requires, in principle, a 3-D mathematical model, it was decided to develop, for simplicity in the first instance, a 2-D finite element analysis. The results obtained will not be reported in detail here but were used to prepare the experimental tests and to extract preliminary conclusions about the effect of the vibration of the cables on the global dynamic response of the bridge.

In a second phase, modal parameters were evaluated based on two 3-D finite element models of the Jindo Bridge physical model. These models were designated, according to AbdelGhaffar and Khalifa15, as OECS (One-Element Cable System) and MECS (Multi-Element Cable System) models. The OECS model discretized the deck and towers into 216 3-D beam elements (120, 80 and 16, for the deck, A-towers and piers, respectively) and idealized each stay cable as a simple truss element with an equivalent Young's modulus. Fifty six additional rigid link elements were added along the girder, in correspondence with added masses and cable end attachments (Figure 3). Forty eight additional elements of the same type were added at the top 
of the towers, in order to simulate the accurate length of the cables. Eleven additional stiff beam elements, connecting horizontally the two legs of each A-tower at the top, were also included, in order to obtain compatible displacements in conformance with the physical model. The MECS model adopted the same discretization of the deck and towers, and each stay cable was discretized into a total number of 12 truss elements.

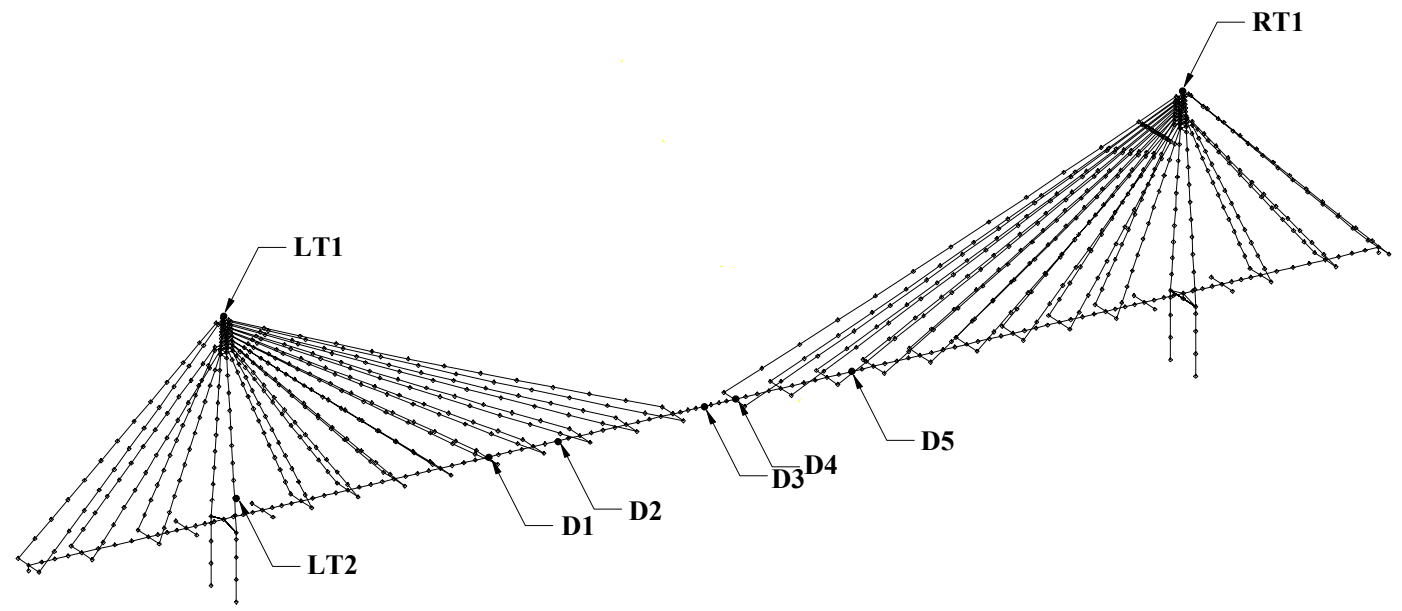

Figure 3. Structural discretization used in the MECS model

The following boundary conditions were assumed in both models: (i) the piers were clamped to the soil; (ii) the vertical displacements, as well as the rotations around the longitudinal and vertical axes were precluded at the end supports of the deck; (iii) the transversal motion of the deck at the end and left tower supports was constrained by appropriate spring elements; (iv) additional constraints at the intermediate supports of the deck over the piers were introduced in order to ensure compatibility of the deck and pier motions, imposing equal vertical displacements at the left support (Figure 3) and equal transversal and vertical displacements at the right one. The introduction of the design initial cable tensions was achieved iteratively by successive adjustment of the initial strain of the stay cables.

Using these models, dynamic analyses ${ }^{20}$ were performed using the stiffness matrix obtained at the end of a geometric non-linear static analysis under permanent loads and a consistent mass matrix, which included in particular the rotational mass moments associated with the steel added masses along the deck and tower legs.

The lowest 20 natural frequencies in the range $0-46 \mathrm{~Hz}$ and the corresponding modal shapes were evaluated for the OECS. Table IV summarizes the values of these frequencies and 
the type of the corresponding modal shapes (SYM- mode shape of the girder and towers is approximately symmetric with respect to the axis of symmetry of the bridge; ASM- mode shape of the girder and towers is approximately anti-symmetric; LTW- mode shape involves essentially the movement of the left tower; RTW- mode shape involves essentially the movement of the right tower). For the MECS, the lowest 150 natural frequencies in the range 0 21.3 Hz and the corresponding modal shapes were calculated. Table V summarizes the values of some of these natural frequencies. It is worth mentioning that, for the first 6 modes obtained on the basis of the OECS model, there was no coupling between in-plane and out-of-plane motion, the first torsional mode occurring only at $22.1 \mathrm{~Hz}$. Note that the non-existence of coupling between bending and torsion in terms of the first 6 natural frequencies led, in this case, to a significant proximity of the results provided by the 2-D and 3-D numerical models used to analyse the structural dynamic response. However, the value of $22.1 \mathrm{~Hz}$ is not really representative of the prototype torsional fundamental frequency, as the physical model did not respect the similarity requirements for the torsional behaviour.

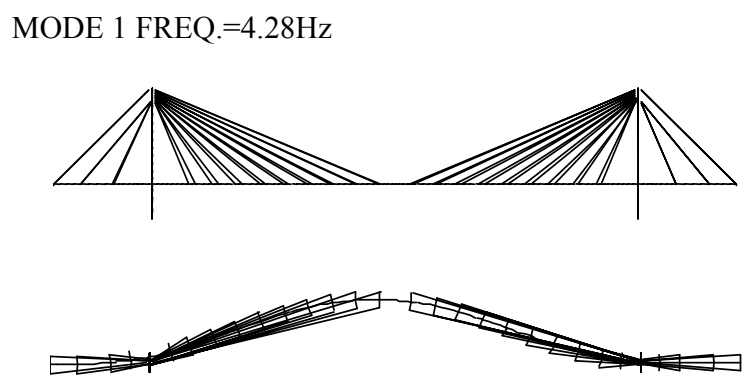

MODE 2 FREQ. $=6.21 \mathrm{~Hz}$

MODE 3 FREQ. $=9.12 \mathrm{~Hz}$

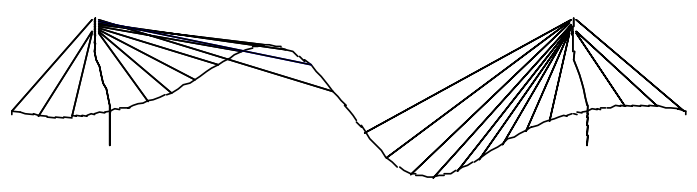

MODE 4 FREQ. $=11.71 \mathrm{~Hz}$
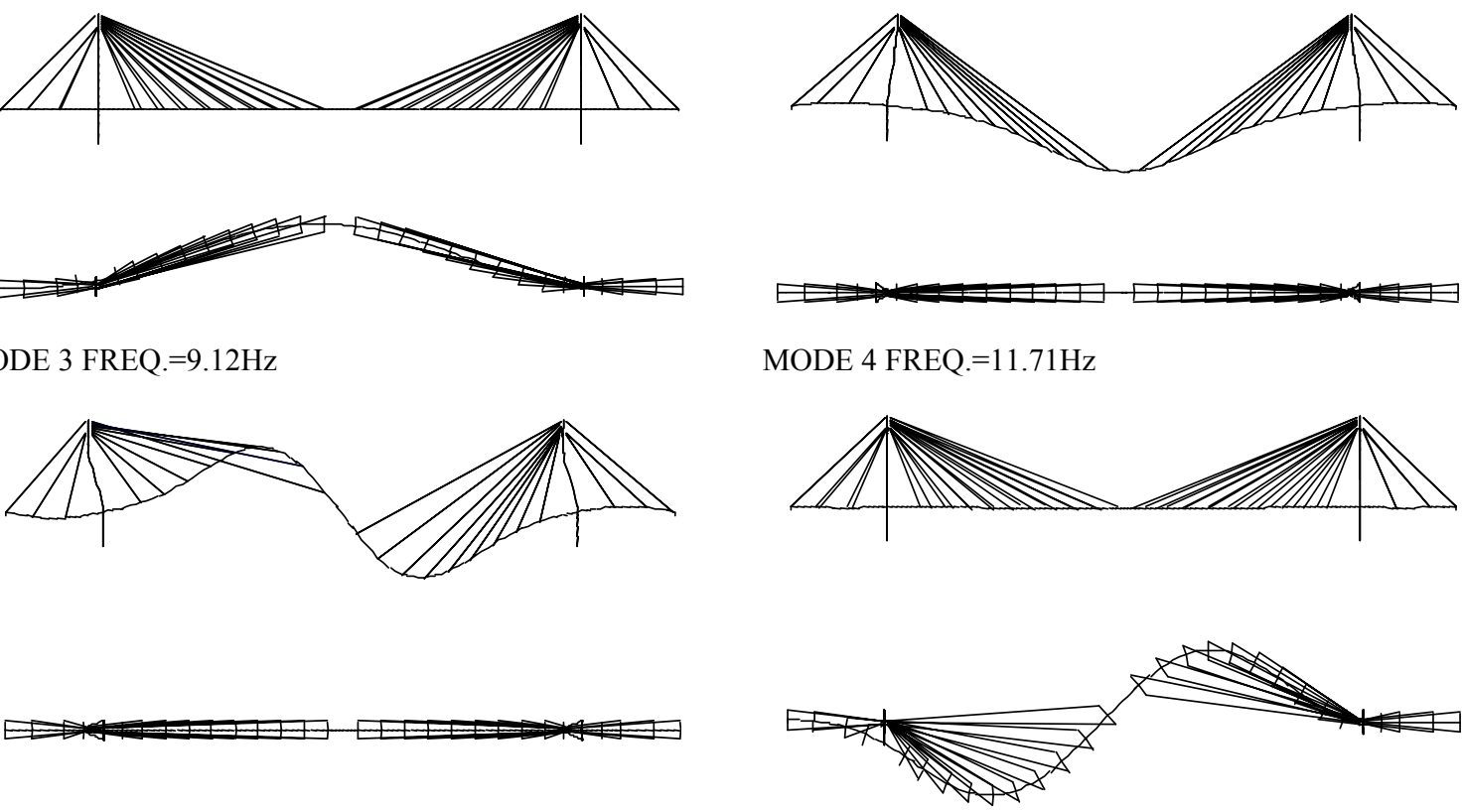

Figure 4. Some calculated modal shapes (OECS analysis)

Table IV. Calculated natural frequencies of Jindo Bridge model (3-D OECS numerical model) 


\begin{tabular}{cccccc}
\hline $\begin{array}{c}\text { Mode } \\
\text { number }\end{array}$ & $\begin{array}{c}\text { Natural } \\
\text { freq. }(\mathrm{Hz})\end{array}$ & Type of Mode & $\begin{array}{c}\text { Mode } \\
\text { number }\end{array}$ & $\begin{array}{c}\text { Natural } \\
\text { freq. }(\mathrm{Hz})\end{array}$ & Type of Mode \\
\hline 1 & 4.28 & $1^{\text {st }}$ transversal SYM & 11 & 24.95 & $1^{\text {st }}$ torsion SYM \\
2 & 6.21 & $1^{\text {st }}$ vertical SYM & 12 & 26.00 & $3^{\text {rd }}$ vertical ASM \\
3 & 9.12 & 1st vertical ASM & 13 & 28.61 & $4^{\text {th }}$ vertical SYM \\
4 & 11.71 & $1^{\text {st }}$ transversal ASM & 14 & 30.33 & $4^{\text {th }}$ vertical ASM \\
5 & 13.74 & 2nd vertical SYM & 15 & 30.45 & transversal \\
6 & 18.26 & 2nd vertical ASM & 16 & 30.46 & $5^{\text {th }}$ vertical SYM \\
7 & 22.10 & $2^{\text {nd }}$ transv.SYM+1 $+1^{\text {st }}$ torsion SYM & 17 & 32.52 & $5^{\text {th }}$ vertical ASM \\
8 & 22.70 & 3rd vertical SYM & 18 & 38.80 & $2^{\text {nd }}$ transv.ASM+1 $1^{\text {st }}$ torsion ASM \\
9 & 23.42 & $1^{\text {st }}$ LTW & 19 & 39.69 & $6^{\text {th }}$ vertical SYM \\
10 & 23.42 & $1^{\text {st }}$ RTW & 20 & 45.11 & $1^{\text {st }}$ torsion ASM $+2^{\text {nd }}$ transv.ASM \\
\hline
\end{tabular}

MODE 1 FREQ. $=4.26 \mathrm{~Hz}$

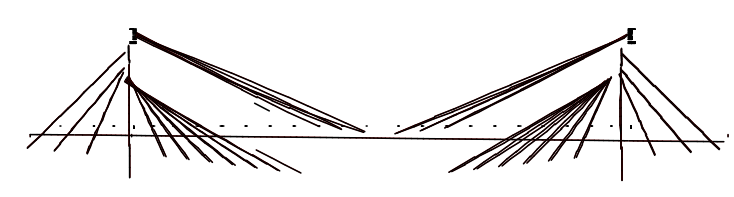

MODE 2 FREQ. $=6.14 \mathrm{~Hz}$
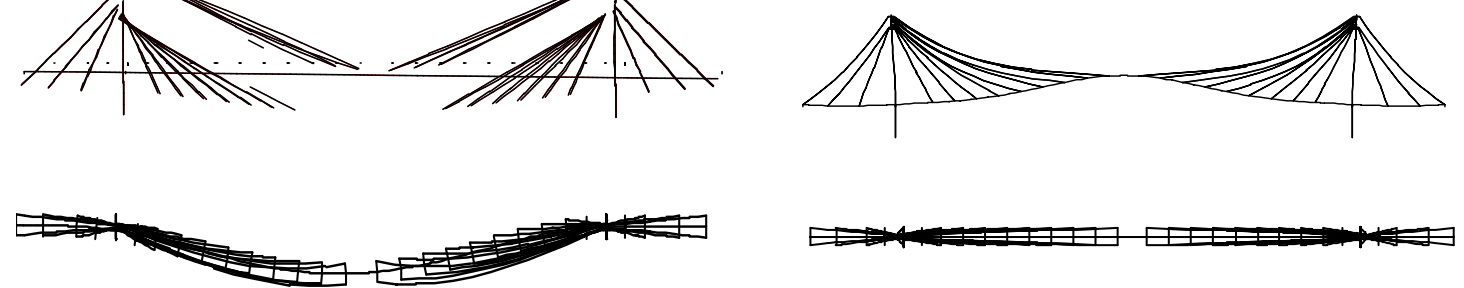

MODE 27 FREQ. $=9.04 \mathrm{~Hz}$

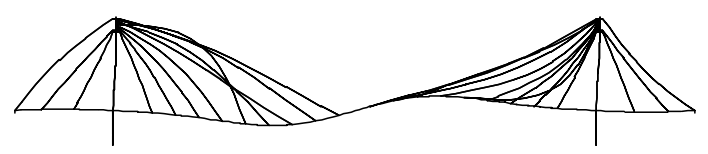

MODE 52 FREQ. $=11.66 \mathrm{~Hz}$
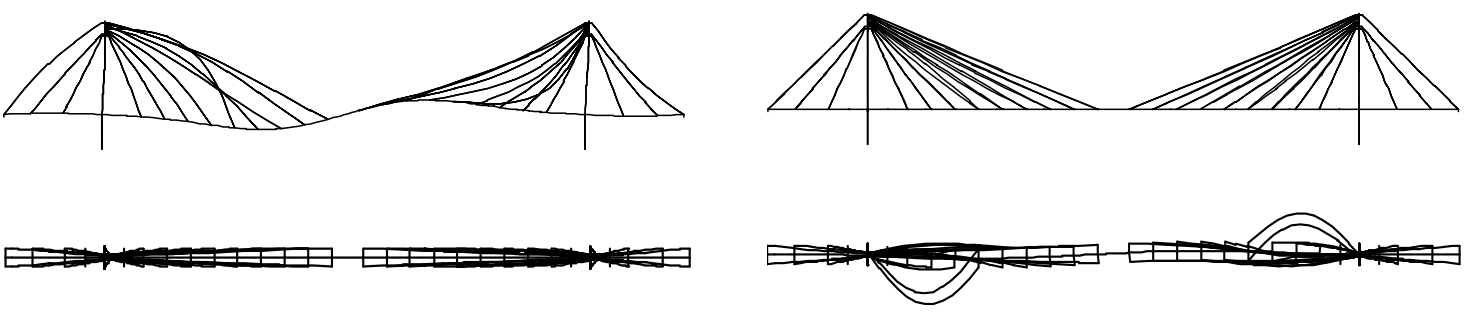

Figure 5. Some calculated modal shapes (MECS analysis)

Analysis of tables IV and V and the observation of the modal shapes (see Figures 4-5) led to the conclusion that the MECS analysis, based on the discretization of the cables into several truss elements, produced many new modes of vibration. Most of the new modes simply involved local vibrations of the cables and so were not important in terms of the contribution to the global response of the bridge. Others of these new modes, however, involved simultaneous motion of the cables and of the deck and towers. In most cases, several of these modes of vibration had close natural frequencies and similar mode shapes for the deck/towers system, but different movements of the cables, the relative order of magnitude of the motion also varying (see Figure 6). The analysis of the mode shapes showed that significant cable interaction occurred in a large number of modes, which could be subdivided into two groups. A first group 
was formed by modes of a vertical nature that presented a strong interaction in the vertical plane, associated with small ratios between the maximum vertical components of the normalized nodal displacements of the group of cables and of the deck/towers system (Z-ratio), though showing also in many cases large out-of-plane cable displacements. A second group corresponded to transversal modes with a strong interaction for out-of-plane motions (small Yratios), though showing frequently large in-plane cable displacements. So, small values either of the Z-ratio or of the Y-ratio (indicated in bold type in Table V) denoted a very clear interaction between the cables and the girder/towers movement. High ratio values were typical of modal shapes that involved essentially vibration of one or more cables, here designated as local modes.

Table V. Calculated natural frequencies of Jindo Bridge Model (3-D MECS numerical model)

\begin{tabular}{|c|c|c|c|c|c|c|}
\hline Mode number & $\begin{array}{c}\text { MECS } \\
\text { natural } \\
\text { frequency } \\
(\mathrm{Hz})\end{array}$ & $\begin{array}{l}\text { Associated } \\
\text { OECS } \\
\text { frequency } \\
(\mathrm{Hz})\end{array}$ & $\begin{array}{c}\text { Ratio of } \\
\text { participation } \\
\text { factors } \\
(\mathrm{Z} / \mathrm{Y})\end{array}$ & $\begin{array}{c}\text { Ratio of } \\
\text { cable/beam } \\
\text { max. displ } \\
\text { (Z-ratio). }\end{array}$ & $\begin{array}{l}\text { Ratio of } \\
\text { cable/beam } \\
\text { max. disp } \\
\text { (Y-ratio). }\end{array}$ & Type of mode \\
\hline 1 & 4.26 & 4.28 & $<1$ & 532.1 & 1.1 & $1^{\text {st }}$ transv. SYM \\
\hline 2 & 6.14 & 6.21 & $>1$ & 1.0 & 1066.4 & $1^{\text {st }}$ vert. SYM \\
\hline 4 & 6.94 & 6.21 & $>1$ & 6.1 & 205509.8 & $1^{\text {st }}$ vert. SYM \\
\hline 5 & 6.94 & 6.21 & $>1$ & 5.8 & 1845228.0 & $1^{\text {st }}$ vert. SYM \\
\hline 9 & 7.15 & 11.71 & $<1$ & 77919.0 & 3.3 & $1^{\mathrm{ST}}$ transv. ASM \\
\hline 10 & 7.16 & 4.28 & $<1$ & 83074.8 & 16.2 & $1^{\mathrm{ST}}$ transv. SYM \\
\hline 12 & 7.93 & 9.12 & $>1$ & 8.4 & 148279.8 & $1^{\text {st }}$ vert. ASM \\
\hline 13 & 7.93 & 9.12 & $>1$ & 8.0 & 2257478.0 & $1^{\text {st }}$ vert. ASM \\
\hline 17 & 8.11 & 11.71 & $<1$ & 76110.7 & 8.3 & 1st transv. ASM \\
\hline 18 & 8.11 & 11.71 & $<1$ & 77946.7 & 19.9 & 1st transv. ASM \\
\hline 20 & 8.42 & 9.12 & $>1$ & 3.8 & 114344.9 & 1st vert. ASM \\
\hline 21 & 8.42 & 9.12 & $>1$ & 3.7 & 3830175.0 & 1st vert. ASM \\
\hline 25 & 8.61 & 11.71 & $<1$ & 69048.1 & 3.2 & 1st transv. ASM \\
\hline 26 & 8.61 & 11.71 & $<1$ & 65279.4 & 17.3 & $1^{\text {st }}$ transv. ASM \\
\hline 27 & 9.04 & 9.12 & $>1$ & 1.6 & 2673.4 & 1st vert. ASM \\
\hline 29 & 9.63 & 9.12 & $>1$ & 7.3 & 77529.4 & 1st vert. ASM \\
\hline 30 & 9.63 & 9.12 & $>1$ & 7.3 & 9995453.0 & 1st vert. ASM \\
\hline 38 & 9.79 & 11.71 & $<1$ & 42457.2 & 28.6 & $1^{\text {st }}$ transv. ASM \\
\hline 39 & 9.79 & 11.71 & $<1$ & 60449.4 & 30.4 & $1^{\text {st }}$ transv. ASM \\
\hline 41 & 9.90 & 11.71 & $<1$ & 51944.1 & 19.4 & $1^{\text {st }}$ transv. ASM \\
\hline 42 & 9.90 & 11.71 & $<1$ & 35404.6 & 11.7 & $1^{\text {st }}$ transv. ASM \\
\hline 46 & 11.36 & 13.74 & $>1$ & 5.8 & 1065667.0 & $2^{\text {nd }}$ vert. SYM \\
\hline 47 & 11.36 & 13.74 & $>1$ & 6.4 & 118704.9 & $2^{\text {nd }}$ vert. SYM \\
\hline 48 & 11.45 & 13.74 & $>1$ & 37.2 & 29824.1 & $2^{\text {nd }}$ vert. SYM \\
\hline 49 & 11.47 & 13.74 & $>1$ & 35.2 & 17452.5 & $1^{\text {st }}$ vert. ASM \\
\hline 50 & 11.48 & 11.71 & $<1$ & 6395.6 & 7.8 & $1^{\text {st }}$ transv. ASM \\
\hline 51 & 11.49 & 11.71 & $<1$ & 5927.5 & 24.9 & $1^{\text {st }}$ transv. ASM \\
\hline 52 & 11.66 & 11.71 & $<1$ & 696.4 & 11.3 & $1^{\text {st }}$ transv. ASM \\
\hline 55 & 12.00 & 13.74 & $>1$ & 12.4 & 248350.0 & $2^{\text {nd }}$ vert. SYM \\
\hline 57 & 12.13 & 11.71 & $<1$ & 12735.4 & 26.4 & $1^{\text {st }}$ transv. ASM \\
\hline 59 & 12.14 & 11.71 & $<1$ & 14815.6 & 17.7 & $1^{\text {st }}$ transv. ASM \\
\hline 60 & 12.16 & 11.71 & $<1$ & 5180.5 & 23.4 & 1st transv. ASM \\
\hline 61 & 13.55 & 13.74 & $>1$ & 6.4 & 8786.0 & $2^{\text {nd }}$ vert. SYM \\
\hline 63 & 13.75 & 13.74 & $>1$ & 18.6 & 795354.8 & $2^{\text {nd }}$ vert. SYM \\
\hline 69 & 13.91 & 13.74 & $>1$ & 35.3 & 42291.0 & $2^{\text {nd }}$ vert. SYM \\
\hline 77 & 14.12 & 13.74 & $>1$ & 12.3 & 19593.1 & $2^{\text {nd }}$ vert. SYM \\
\hline
\end{tabular}

MODE 17 FREQ.=8.11Hz
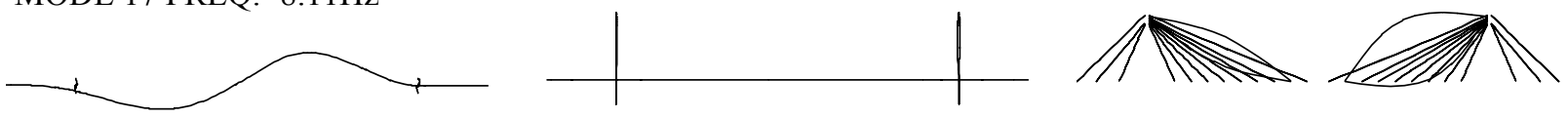


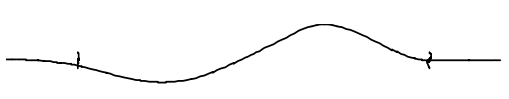

MODE 21 FREQ. $=8.42 \mathrm{~Hz}$

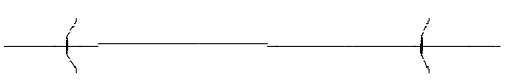

MODE 27 FREQ. $=9.04 \mathrm{~Hz}$

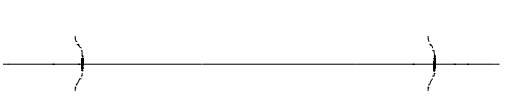

(a)
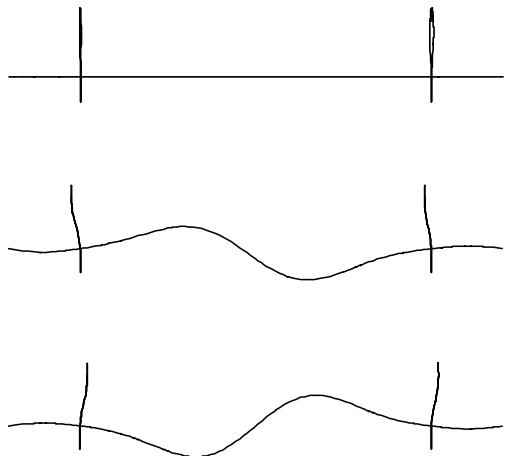

(b)
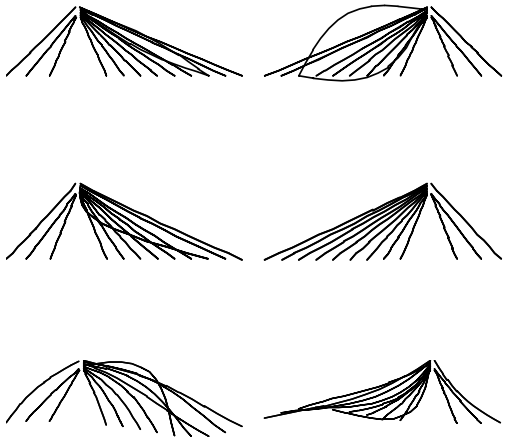

(c)

Figure 6. Some calculated modal shapes (MECS analysis): separated representation of cables and deck/towers motion (plan (a) and vertical views (b,c))

\section{EXPERIMENTAL MODAL SURVEY}

\subsection{Test procedures}

The identification of modal parameters from the physical model was based on the use of an electrodynamic shaker. The procedure consisted of the application of vertical and transversal multi-sine excitation at the mid-span (node D3) and at the one third points of the span (left, node D2 ; right, node D5). The response was measured along the deck and towers using a small piezoelectric accelerometer, and along some of the cables, either using the piezoelectric accelerometer (only on the back-stays) or a magnetic sensor. Force was measured by means of a force sensor, interposed between the shaker and the bridge model.

The acquired time signals were used to obtain frequency response functions (FRFs). Modal parameters were extracted from the set of FRFs using a least squares frequency domain identification algorithm ${ }^{21}$, based on the Rational Fraction Polynomial Method.

Figures 7 and 8 illustrate some examples of measured FRFs and associated coherence estimates for the range $0-100 \mathrm{~Hz}$. The corresponding synthesized functions, based on the mentioned identification algorithm are also presented. Except for the range $0-10 \mathrm{~Hz}$, where the noise to signal ratio is more significant, high coherence values were generally achieved, giving evidence of high quality measurements. 

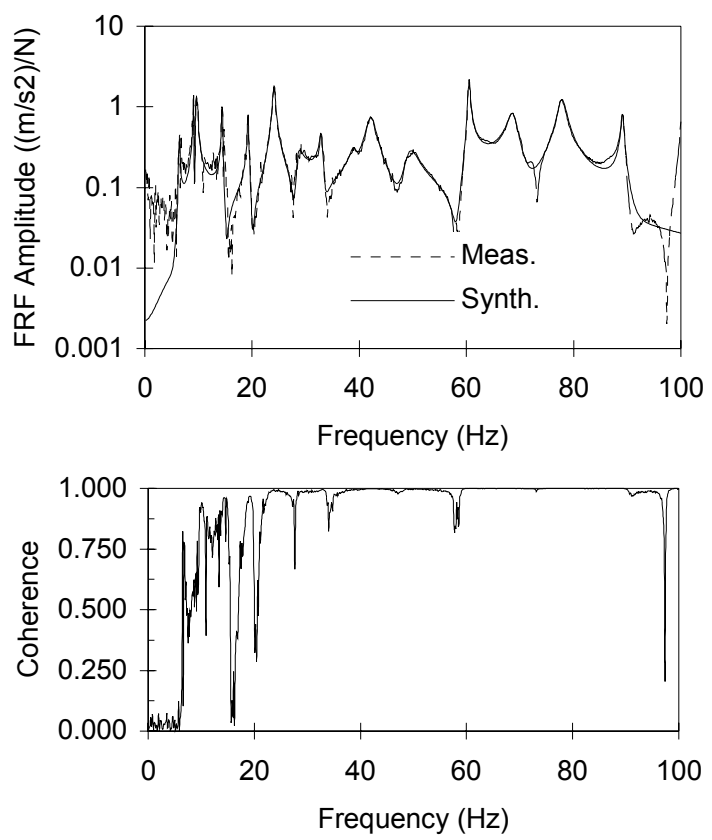

Figure 7. Coherence and FRF measured / synthesized from node D5 vertical (excitation) to node D1 vertical (response)
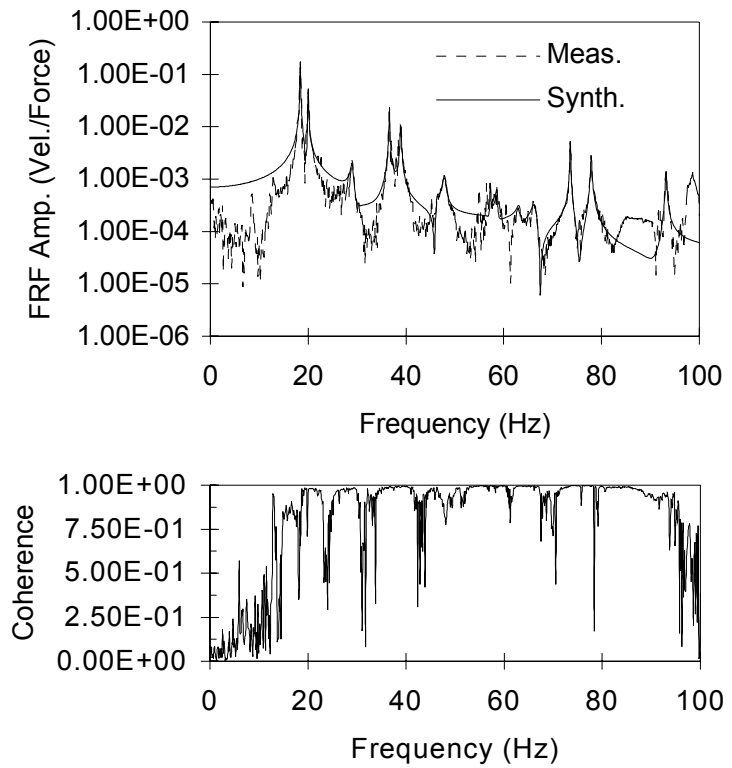

Figure 8. FRF and Coherence measured / synthesized from node D5 vertical (excitation) to cable 8 (left, back) between 10th and 11th masses from bottom (in-plane response) 


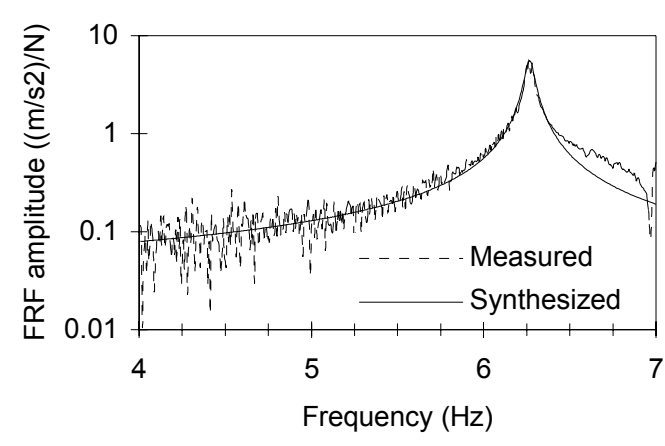

(a)

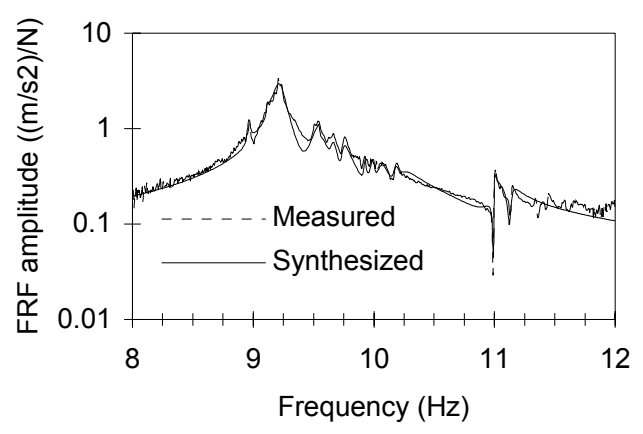

(b)

Figure 9. (a) Zoom FRF measured / synthesized from node D5 vertical (excitation) to node D3 vertical (response); (b) Zoom FRF measured / synthezised from node D5 vertical (excitation) to node D2 vertical (response)
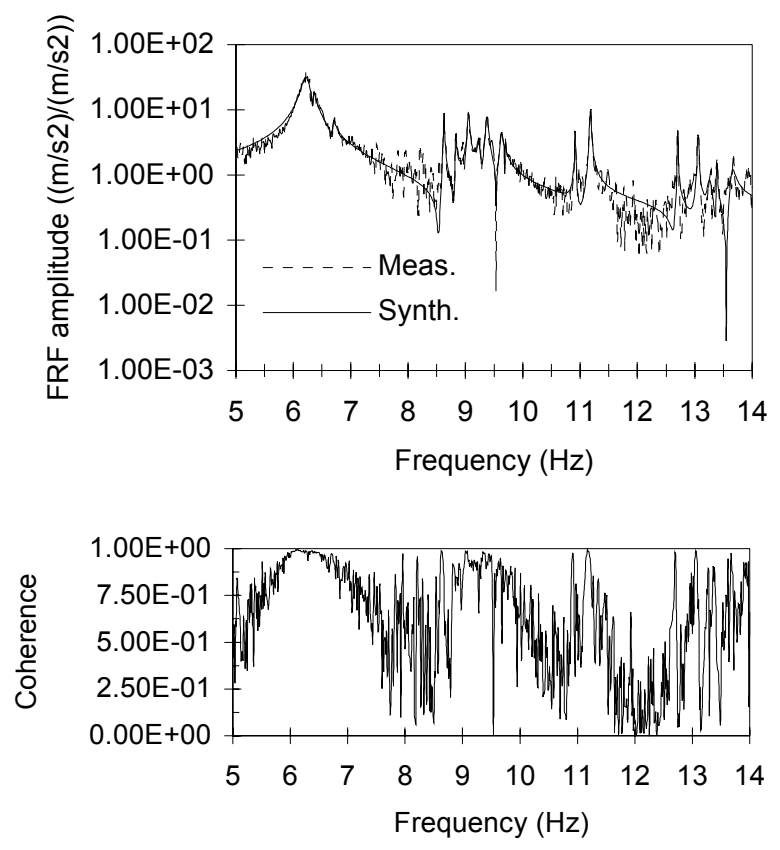

Figure 10. FRF and Coherence measured / synthesized from acceleration at the platform to node D5 vertical (response)

Figure 9 presents some high quality FRF zooms performed in the low frequency range, clearly showing the existence of several multiple vertical modes in the range $9-10 \mathrm{~Hz}$.

Similar modal analysis tests were performed on a 6-DOF shaking table, by application of a multi-sine base excitation (along the longitudinal, $\mathrm{X}$, transversal, $\mathrm{Y}$, and vertical, $\mathrm{Z}$, directions) and by measurement of the structural response in terms of accelerations and displacements along the deck and towers. Very good coherence function estimates were found in the range $0-50 \mathrm{~Hz}$ for the set of FRFs (obtained from the relation between the measured 
response and the measured acceleration on the shaking table) and, most important, there was high consistency between the data obtained from these two different forms of excitation. Figure 10 presents an example of a measured / synthesized FRF and associated coherence function estimates.

\subsection{Test results}

Table VI summarizes the average values and the intervals of variation of the natural frequencies and damping factors, respectively, that were identified in the range 0-50 Hz. These were obtained from the set of FRF estimates associated with in-plane and out-of-plane excitation and response measurements, employing both types of excitation, electrodynamic shaker and shaking table tests.

Inspection of this table shows the consistency between measurements performed under excitation from the electrodynamic shaker and on the shaking table. Some slight differences obtained may be explained by perturbations induced by the shaker. In certain cases it was not possible to identify accurately some of the multiple modes simultaneously with both excitation techniques, due to high modal interference and insufficient amplitude and/or frequency resolution of the FRF estimates.

It is important to note the significant variation of the identified damping factors, which seem to be highly dependent on the amplitude of vibration and also on the duration of the excitation. This fact is particularly relevant for the damping factors associated to the first transversal and vertical bending modes of vibration, whose magnitudes also attained values much superior to other modes.

Table VII summarizes calculated natural frequencies based on the OECS and MECS models, as well as the corresponding average values of the identified natural frequencies, obtained from the shaking table measurements. These frequencies are grouped according to the deck/towers configuration of the associated mode shapes. 
Table VI. Identified natural frequencies and damping factors

\begin{tabular}{|c|c|c|c|c|}
\hline \multirow[t]{2}{*}{ Type of mode } & \multicolumn{2}{|c|}{$\begin{array}{l}\text { Identified natural frequency } \\
\qquad(\mathrm{Hz})\end{array}$} & \multicolumn{2}{|c|}{$\begin{array}{c}\text { Measured damping factor } \\
(\%)\end{array}$} \\
\hline & Shaker & Shaking table & Shaker & Shaking table \\
\hline $1^{\text {st }}$ transv. SYM & $3.95 \pm 0.10$ & $3.91 \pm 0.09$ & - & $1.65-2.08$ \\
\hline $1^{\text {st }}$ vert. SYM & $6.25 \pm 0.08$ & $6.27 \pm 0.10$ & $0.42-1.33$ & $0.35-1.67$ \\
\hline $1^{\text {st }}$ vert. SYM & $6.69 \pm 0.06$ & $6.73 \pm 0.03$ & $0.60-0.87$ & $0.11-0.43$ \\
\hline $1^{\text {st }}$ vert. SYM & $7.12 \pm 0.06$ & & $0.52-0.91$ & \\
\hline $1^{\text {st }}$ vert. ASM & $8.96 \pm 0.02$ & $8.63 \pm 0$ & $0.13-0.16$ & $0.060-0.069$ \\
\hline $1^{\text {st }}$ vert. ASM & & $8.82 \pm 0.01$ & & $0.092-0.097$ \\
\hline $1^{\text {st }}$ vert. ASM & $9.16 \pm 0.06$ & $9.05 \pm 0.01$ & $0.15-1.18$ & $0.14-0.18$ \\
\hline $1^{\text {st }}$ vert. ASM & & $9.25 \pm 0.01$ & & $0.18-0.25$ \\
\hline $1^{\text {st }}$ vert. ASM & $9.52 \pm 0.11$ & $9.37 \pm 0.06$ & $0.15-0.78$ & $0.19-0.25$ \\
\hline $1^{\text {st }}$ vert. ASM & $9.62 \pm 0.09$ & $9.49 \pm 0.04$ & $0.36-0.62$ & $0.11-0.15$ \\
\hline $1^{\text {st }}$ vert. ASM & $9.74 \pm 0.01$ & $9.63 \pm 0.03$ & $0.19-0.22$ & $0.15-0.29$ \\
\hline $1^{\text {st }}$ vert. ASM & $10.08 \pm 0.16$ & & $0.14-0.30$ & \\
\hline $1^{\text {st }}$ vert. ASM & $11.00 \pm 0.01$ & $10.90 \pm 0.02$ & $0.15-0.17$ & $0.043-0.049$ \\
\hline $1^{\text {st }}$ vert. ASM & $11.14 \pm 0.01$ & $11.18 \pm 0.01$ & $0.10-0.14$ & $0.037-0.099$ \\
\hline $1^{\text {st }}$ transv. ASM & & 9.10 & & 0.34 \\
\hline $1^{\text {st }}$ transv. ASM & & 9.19 & & 0.25 \\
\hline $1^{\text {st }}$ transv. ASM & $9.62 \pm 0$ & & $0.58-0.59$ & \\
\hline $1^{\text {st }}$ transv. ASM & $10.10 \pm 0.08$ & & $0.60-0.90$ & \\
\hline $1^{\text {st }}$ transv. ASM & $10.27 \pm 0.02$ & $10.35 \pm 0.11$ & $0.28-0.30$ & $0.52-1.73$ \\
\hline $1^{\text {st }}$ transv. ASM & $10.58 \pm 0.06$ & $10.54 \pm 0.08$ & $0.18-1.08$ & $0.65-1.16$ \\
\hline $1^{\text {st }}$ transv. ASM & & 10.73 & & 0.60 \\
\hline $1^{\text {st }}$ transv. ASM & $10.95 \pm 0.01$ & 10.98 & $0.08-0.12$ & 0.094 \\
\hline $1^{\text {st }}$ transv. ASM & $11.00 \pm 0.03$ & & $0.10-0.33$ & \\
\hline $1^{\text {st }}$ transv. ASM & $11.18 \pm 0.11$ & $11.17 \pm 0.03$ & $0.03-0.82$ & $0.81-1.13$ \\
\hline $1^{\text {st }}$ transv. ASM & $11.48 \pm 0.03$ & 11.49 & $0.02-0.25$ & 0.12 \\
\hline $1^{\text {st }}$ transv. ASM & $11.52 \pm 0.01$ & & $0.21-0.32$ & \\
\hline $1^{\text {st }}$ transv. ASM & & $11.62 \pm 0.01$ & & $0.13-0.53$ \\
\hline $1^{\text {st }}$ transv. ASM & $11.88 \pm 0.03$ & & $0.05-0.45$ & \\
\hline $1^{\text {st }}$ transv. ASM & & 12.45 & & 0.14 \\
\hline $1^{\text {st }}$ transv. ASM & & 12.66 & & 0.11 \\
\hline $1^{\text {st }}$ transv. ASM & & 12.79 & & 0.17 \\
\hline $1^{\text {st }}$ transv. ASM & & 12.82 & & 0.61 \\
\hline $1^{\text {st }}$ transv. ASM & & 12.96 & & 0.64 \\
\hline $2^{\text {nd }}$ vert. SYM & $14.44 \pm 0.12$ & $14.36 \pm 0.04$ & $0.24-0.61$ & $0.041-0.69$ \\
\hline $2^{\text {nd }}$ vert. SYM & $14.75 \pm 0.09$ & $14.51 \pm 0.01$ & & $0.097-0.21$ \\
\hline $2^{\text {nd }}$ vert. SYM & & $14.80 \pm 0.02$ & & $0.16-0.24$ \\
\hline $2^{\text {nd }}$ vert. ASM & $18.74 \pm 0.05$ & & $0.46-0.92$ & \\
\hline $2^{\text {nd }}$ vert. ASM & $19.05 \pm 0.02$ & $19.16 \pm 0.08$ & $0.16-0.25$ & $0.039-0.47$ \\
\hline $2^{\text {nd }}$ vert. ASM & $19.23 \pm 0.07$ & $19.29 \pm 0.09$ & $0.14-1.09$ & $0.16-0.41$ \\
\hline $2^{\text {nd }}$ transv.SYM $+1^{\text {st }}$ torsion $S Y M$ & & $20.24 \pm 0.08$ & & $0.86-1.24$ \\
\hline $2^{\text {nd }}$ transv.SYM $+1^{\text {st }}$ torsion $S Y M$ & & $21.61 \pm 0.03$ & & $0.07-0.32$ \\
\hline $2^{\text {nd }}$ transv.SYM $+1^{\text {st }}$ torsion SYM & & $21.97 \pm 0.15$ & & $0.06-0.16$ \\
\hline $2^{\text {nd }}$ transv.SYM $+1^{\text {st }}$ torsion SYM & & $22.26 \pm 0$ & & $0.01-0.28$ \\
\hline $2^{\text {nd }}$ transv.SYM $+1^{\text {st }}$ torsion SYM & $23.24 \pm 0.09$ & $23.62 \pm 0.17$ & $0.14-0.47$ & $0.038-0.098$ \\
\hline $3^{\text {rd }}$ vert. SYM & $24.10 \pm 0.33$ & $23.89 \pm 0.12$ & & $0.51-1.35$ \\
\hline $1^{\text {st }}$ torsion $\mathrm{SYM}$ & $25.19 \pm 0.01$ & & & $0.14-0.15$ \\
\hline $1^{\text {st }}$ torsion SYM & $25.49 \pm 0.01$ & & & $0.42-0.45$ \\
\hline $3^{\text {rd }}$ vert. ASM & $29.61 \pm 0.67$ & $27.59 \pm 0.06$ & $0.16-1.51$ & $0.13-0.87$ \\
\hline $4^{\text {th }}$ vert. SYM & $30.48 \pm 0.52$ & $29.68 \pm 0.56$ & $0.24-1.80$ & $0.33-1.88$ \\
\hline $4^{\text {th }}$ vert. ASM & $32.99 \pm 0.12$ & $33.42 \pm 0.09$ & $0.57-0.86$ & $0.32-0.67$ \\
\hline $5^{\text {th }}$ vert. SYM & $39.33 \pm 1.73$ & $41.08 \pm 0.53$ & $0.96-2.06$ & $0.63-1.22$ \\
\hline $5^{\text {th }}$ vert. SYM & $42.18 \pm 1.58$ & & $0.87-2.29$ & \\
\hline $5^{\text {th }}$ vert. ASM & $49.35 \pm 0.38$ & & $0.28-2.91$ & \\
\hline
\end{tabular}


Inspection of the FRFs and of Tables VI and VII shows the existence of several very close natural frequencies in the vicinity of each of the natural frequencies obtained from the OECS analysis. This is probably due to the close proximity of the first natural frequencies of several cables with one of the natural frequencies of the global structure. This fact is more evident for the first transversal and vertical anti-symmetric modes obtained from the OECS analysis, as a significant number of modes have been identified. The FRF zoom presented in Figure 9 (b), for instance, permitted the identification of nine vertical modes of vibration, at the frequencies $8.63 \mathrm{~Hz}, 8.83 \mathrm{~Hz}, 9.06 \mathrm{~Hz}, 9.24 \mathrm{~Hz}, 9.53 \mathrm{~Hz}, 9.62 \mathrm{~Hz}, 9.70 \mathrm{~Hz}, 10.92 \mathrm{~Hz}$ and 11.18 Hz.

Table VII. Identified and calculated natural frequencies

\begin{tabular}{|c|c|c|c|}
\hline Type of mode & $\begin{array}{l}\text { OECS: Calculated } \\
\text { natural frequency }(\mathrm{Hz})\end{array}$ & $\begin{array}{l}\text { MECS: Calculated natural frequency } \\
\qquad(\mathrm{Hz})\end{array}$ & Identified natural frequency $(\mathrm{Hz})$ \\
\hline $1^{\text {st }}$ transv. SYM & 4.28 & $4.26 / 7.16$ & 3.91 \\
\hline $1^{\text {st }}$ vert. SYM & 6.21 & $6.14 / 6.94 / 6.94$ & $6.27 / 6.73$ \\
\hline $1^{\text {st }}$ vert. ASM & 9.12 & $\begin{array}{c}7.93 / 7.93 / 8.42 / 8.42 / 9.04 / 9.63 / 9.63 \\
/ 9.69 / 9.69 / 11.47\end{array}$ & $\begin{array}{c}8.63 / 8.82 / 9.05 / 9.25 / 9.37 / \\
9.49 / 9.63 / 10.90 / 11.18\end{array}$ \\
\hline $1^{\text {st }}$ transv. ASM & 11.71 & $\begin{array}{c}7.15 / 8.11 / 8.11 / 8.61 / 8.61 / 9.79 / 9.79 / \\
9.90 / 9.90 / 11.48 / 11.49 / 11.66 / 12.13 / \\
12.14 / 12.16\end{array}$ & $\begin{array}{c}9.10 / 9.19 / 10.35 / 10.54 / 10.73 / \\
10.98 / 11.17 / 11.49 / 11.62 / 12.45 / \\
12.66 / 12.79 / 12.82 / 12.96\end{array}$ \\
\hline $2^{\text {nd }}$ vert. SYM & 13.74 & $\begin{array}{c}11.36 / 11.36 / 11.45 / 11.47 / 12.00 / \\
12.00 / 13.55 / 13.75 / 13.75 / 13.91 / \\
14.12\end{array}$ & $14.36 / 14.51 / 14.80$ \\
\hline $2^{\text {nd }}$ vert. ASM & 18.26 & $17.81 / 18.29$ & $19.16 / 19.29$ \\
\hline $\begin{array}{c}2^{\text {nd }} \text { transv. SYM + } \\
1^{\text {st }} \text { torsion SYM }\end{array}$ & 22.10 & $*$ & $20.24 / 21.61 / 21.97 / 22.26 / 23.62$ \\
\hline $3^{\text {rd }}$ vert. SYM & 22.70 & * & 23.89 \\
\hline $1^{\text {st }}$ torsion SYM & 24.95 & $*$ & $25.19 / 25.49$ \\
\hline
\end{tabular}

An attempt was made to prove that the measured mode shapes involved similar displacements for the girder and towers, and different displacements of the cables, as had been reported for the numerical analysis. Time series were collected at several nodes of the girder and towers, measuring the response to a sinusoidal excitation applied vertically at node D5 with frequencies of $9.20 \mathrm{~Hz}$ and $9.50 \mathrm{~Hz}$. From these series, components of the two mode shapes were estimated. Figure 11, representing a plot of these components against the associated values for the 1st vertical anti-symmetric mode obtained from the OECS analysis, shows the similarity of configurations of the mode shapes. 


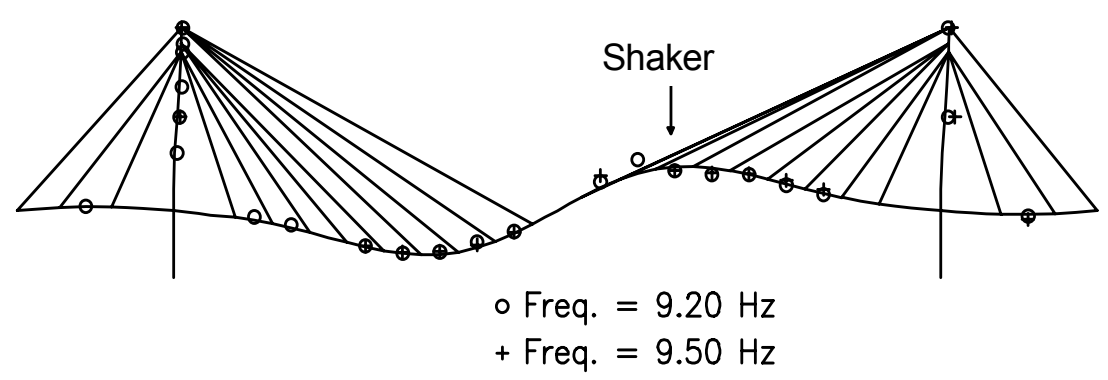

Figure 11. Identified and calculated mode shapes

With regard to the cables, it was visually observed that sinusoidal excitations applied at closely spaced frequencies induced different movements of the cables. Moreover, for the levels of vibration induced, the persistence of the excitation showed no evidence of inducing a modification of the configurations of vibration (either of the girder/towers or of the cables) into other configurations (for instance, the configuration of adjacent modes of vibration). It was also observed that the repetition of some sinusoidal excitations at different times and with different initial conditions did not induce different movements of the cables. Table VIII reports the observed movement of the cables for different frequencies of excitation close to $9 \mathrm{~Hz}$. To distinguish the two cables connected to the upstream and downstream side of the same tower, symbols $D$ (downstream cable) and $U$ (upstream cable) have been employed. The relative

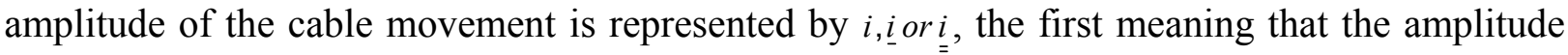
of vibration of cable $i$ was low and the last meaning that this amplitude was quite high.

It is noteworthy that there was in fact a three-dimensional character of the vibration, as the 4 equal stay cables with similar tensions associated with each cable number (e.g.: $8 \mathrm{U}$ left, $8 \mathrm{D}$ left, $8 \mathrm{U}$ right, $8 \mathrm{D}$ right) behaved differently. From Tables VIII and IX, it is clear that the cables with major vibrations were the same in both experimental and numerical analyses. Howerver, there was not a perfect agreement with the results of the 3-D MECS model in terms of the number and value of the identified frequencies or of the corresponding modal shapes. This fact is certainly due to the practical difficulty of achieving an accurate numerical model of local features and slight imperfections of the physical model. 
Table VIII. Observation of cable movement during sinusoidal excitation

\begin{tabular}{|c|c|c|}
\hline Frequency $(\mathrm{Hz})$ & Cables connected to left tower & Cables connected to right tower \\
\hline 9.20 & $\underline{8 D}, \underset{=}{ } \mathrm{U}, \underline{9} D, 9 U, \underline{3} U$ & $\underset{8}{8 U}, \underline{9 D}, \underline{=} U, \underline{5} D, \underline{\underline{J}}$ \\
\hline 9.25 & $\underline{8} D, \underline{=} U, 9 D, 9 U$ & 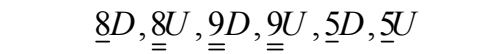 \\
\hline 9.50 & $\stackrel{8 D, 9 D, 9 U, 10 D, 10 U}{=}$ & $\underline{8 D}, \underline{8 U}, \underline{9}=\underline{D}, \underline{9}=\underline{5} \bar{D}, \underline{5 U}, 12 \mathrm{D}, 12 U$ \\
\hline 9.55 & $\stackrel{8 D}{=}, \underline{U} U, 10 \mathrm{D}, 10 \mathrm{U}$ & $8 U, 9 U, 9 D, \underline{5 D}$ \\
\hline
\end{tabular}

Table IX. Description of cable movement using a 3-D MECS analysis

\begin{tabular}{ccc}
\hline Frequency $(\mathrm{Hz})$ & Cables connected to left tower & Cables connected to right tower \\
\hline $\mathbf{7 . 9 3}$ & 11 & 11 \\
$\mathbf{8 . 4 2}$ & 10 & 10 \\
$\mathbf{9 . 0 4}$ & $1,7, \underline{8}, \underline{9}, 10,11,12$ & $1,7, \underline{8}, \underline{9}, 10,11,12$ \\
$\mathbf{9 . 6 3}$ & 9 & 9 \\
$\mathbf{9 . 6 9}$ & 8 & 8 \\
$\mathbf{1 1 . 4 7}$ & 1 & 1 \\
\hline
\end{tabular}

With respect to the FRFs obtained from measurements on the cables, the analysis of peak frequencies revealed not only the frequencies of individual vibration of the cables, but also the existence of other peak values corresponding to natural frequencies measured on the girder/towers associated with global modes of vibration.

\subsection{Accuracy of the analysis}

The analysis presented in the previous sections used two different approaches (experimental and numerical) to determine the dynamic behaviour of a physical model of a cable-stayed bridge, which prompts some reflection about the corresponding accuracy and limitations.

With regard to the experimental analysis, two main sources of error can be identified: the errors associated with instrumentation and data acquisition, and the errors due to the algorithm used in the identification of structural parameters.

The instrument chain used in the shaker test had a 95\% confidence level calibration error of $5 \%$, leading to a maximum $10.6 \%$ error in the amplitude of the FRF estimates. The chain calibrations for the instruments used in the shaking table tests were between $4 \%$ and $5 \%$, giving FRF amplitude errors between $8.3 \%$ and $9.1 \%$. 
The relatively low level of these instrumentation errors, associated with the small frequency resolution adopted (varying between $0.00625 \mathrm{~Hz}$ and $0.1250 \mathrm{~Hz}$ ) and the accurate identification algorithm used (a MDOF algorithm in the frequency domain that allows subinterval curve-fitting and compensation of the effect of the out-of-band modes in manual mode), give confidence in the accuracy of the results.

With regard to the accuracy of the numerical modelling, it is worth noting that it faces some limitations and uncertainties. In fact, the numerical model could not take into account several physical features that can significantly influence the cable behaviour, for example, possible small imperfections in the connections of the cables to the girder and towers, lack of symmetry of the upstream and downstream cables due to the form of distribution of the added masses, as well as possible deviations of the cable tensions in relation to the theoretical values, due to the $5 \%$ tolerance achieved in the cable tensioning. Moreover, some important uncertainties are also related with the constraints of the transversal motion of the deck at the end and left tower supports for transversal motions, and thermal changes are also disregarded.

\section{FINAL CONSIDERATIONS}

The main objective of this paper was to describe an experimental investigation developed by the authors at the Earthquake Engineering Research Centre of the University of Bristol, concerning the experimental study of the dynamic behaviour of the physical model of a cable-stayed bridge. From the set of data analysed, the following conclusions can be drawn:

1. Extensive measurements on the bridge model with associated high coherences showed good correlation with 3-D numerical models, suggesting a good quality of the database created.

2. The modal survey confirmed the existence of interaction between the cables and the deck/towers. This interaction was characterized by the appearance of several modes of vibration with very close natural frequencies and with similar mode shape configurations of the deck and towers, but involving different movements of the cables. The appearance of 
these new mode shapes proved to be conditioned by the closeness between a natural frequency of the global structure and the natural frequencies of some cables. Numerical analysis on the basis of the MECS model showed this aspect, although a perfect agreement between the calculated and the identified modal parameters could not be achieved, probably due to the practical difficulty of an accurate numerical modelling of local particularities and slight imperfections of the physical model.

3. The damping factors identified on the basis of both the modal survey and from the decay tests were in general rather small (less than 1\%) and exhibited a quite wide variation. This variation proved to be related to the amplitude of motion and to the duration of excitation, and was more significant for the first vertical and transversal bending modes of vibration.

\section{ACKNOWLEDGEMENTS}

The present investigation work was carried out at the EERC at the University of Bristol and funded from the Human Capital and Mobility Programme of the European Union, under the ECOEST Programme (European Consortium of Earthquake Shaking Tables) and in conjunction with research contracts from the UK Engineering and Physical Sciences Research Council and from the Portuguese Foundation for Science and Technology (FCT). The writers wish to acknowledge the help of Prof. R. Severn who provided material conditions for this research, as well as the advice of Dr. A. Blakeborough and the technical support of Mr. D. Ward.

\section{REFERENCES}

1. Sethia, M.R. and Krishna, P., "Modal tests of a cable-stayed bridge", Proc. of the int. conf. on cable-stayed bridges, Bangkok, 1987, pp.927-938.

2. Godden, W.G. and Aslam, M., "Dynamic model studies of a Ruck-A-Churcky bridge", Journal of the structural division, ASCE, 104, No.ST12, 1827-1844 (1978). 
3. Garevski, M. A., "Dynamic analysis of cable-stayed bridges by means of analytical and physical modelling", Ph.D. Thesis, Department of Civil Engineering, University of Bristol, U.K. 1990.

4. Stiemer, S.F., Taylor, P. and Vincent, D.H.C., "Full scale dynamic testing of the Annacis bridge", IABSE Periodica, 1, 1-16 (1988).

5. Ohlsson, S.V., "Dynamic characteristics of cable-stayed bridges - Nonlinearities and weakly coupled modes of vibration", Proc. of the int. conf. on cable-stayed bridges, Bangkok, 1987, pp.421-431.

6. Murià-Vila, D., Gomèz, R. and King, C., "Dynamic structural properties of cable-stayed Tampico Bridge", Journal of structural engineering, ASCE, 117, No.11, 3396-3416 (1991).

7. Jakobsen, K.A., Jordet, E., Rambjor, S.K. and Jakobsen, A.A., "Full scale measurements of the behaviour of the Helgeland bridge - A cable-stayed bridge located in a harsh environment", Proc. of the int. symposium on cable dynamics, Liège, 1995, pp.473-480.

8. Cremer, J-M, Counasse, C., Goyet, V.V., Lothaire, A. and Dumortier, A., "The stays, their dynamic behaviour, their equipments - Bridges at Ben-Ahin, Wandre and upon Alzette", Proc. of the int. symposium on cable dynamics, Liège, 1995, pp.489-496.

9. Langsoe, H.E. and Larsen, O.D., "Generating mechanisms for cable stay oscillations at the Faro bridges", Proc. of the int. conf. on cable-stayed bridges, Bangkok, 1987, pp.1023-1033.

10. Persoon, A.J., "The wind induced response of a cable-stayed bridge", Bridge aerodynamics, ICE, 1981, pp.73-77.

11. Lilien, J.L. and Costa, A.P., "Amplitudes caused by parametric excitations on cable stayed structures", Journal of Sound and Vibration, 174(1), 64-90 (1994).

12. Hikami, Y. and Shiraishi, N., "Rain-wind induced vibrations of cables in cable-stayed bridges", Journal of wind engineering and industrial aerodynamics, 29, 409-418, (1988).

13. Ruscheweyh, H. and Verwieke, C., "Rain-wind-induced vibrations of steel bars", Proc. int. conf. on cable-stayed bridges, Bangkok, 1987, pp.469-472.

14. Causevic, M. S. and Sreckovic, G., "Modelling of cable-stayed bridge cables: effects on bridge vibrations", Proc. int. conf. on cable-stayed bridges, Bangkok, 1987, pp.407-420. 
15. Abdel-Ghaffar, A. M. and Khalifa, M. A., "Importance of cable vibration in dynamics of cable-stayed bridges", Journal of engineering mechanics, ASCE, 117, No. 11, 2571-2589 (1990).

16. Caetano, E., Cunha, A. and Taylor, C.A., "Investigation of dynamic cable-deck interaction in a physical model of a cable-stayed bridge. Part II: Seismic response", Earthquake engineering and structural dynamics, submitted for publication (1999).

17. Tappin, G. R., "Jindo and Dolson Bridges", Proc. of the inst. of civil engrs, 78, Part I, 12811300 (1985).

18. Caetano, E. and Cunha, A., "An investigation into the cable dynamics on cable-stayed bridges", Research report, Department of Civil Engineering, University of Bristol, U.K. 1995.

19. Irvine, H. M., "Vibrations of inclined cables", Journal of structural division, ASCE, 104, No. ST2, 343-347 (1978).

20. SOLVIA 95.0 Finite element system, SOLVIA Engineering AB, Sweden, 1995.

21. Han, M-C and Wicks, A.L., "On the application of Forsythe orthogonal polynomials for global modal parameter estimation", Proc. 7th int. modal analysis conf., 1989, pp.625-630. 